- Maintenance of oral health and access to dental treatment is a problem for disabled elderly people.

- A retrospective audit of new referrals of elderly people requiring domiciliary care in one area

of West Hertfordshire Community Dental Service was carried out .

- The audit considered whether the demand of new domiciliary referrals was being met.

\title{
Who will provide dental care for housebound people with oral problems?
}

\author{
D. Simons ${ }^{1}$
}

There are currently 91/2 million people in England and Wales over retirement age and nearly 4 million of these are over 75 years. ${ }^{1}$ Age itself is not a disease and $70 \%$ of the population over 65 are functionally independent. However, ageing is associated with an increase in the prevalence of chronic disease and disability ${ }^{2}$ and $20 \%$ of people over 65 years are frail and a further 10\% are functionally dependent, either homebound or institutionalised. ${ }^{3}$ The implications of this demographic change on oral health has been investigated. Reports show oral health for the well elderly is improving, ${ }_{1}^{4}$ creating a demand for dental services, which this group are able to access, but maintenance of oral health and access to dental treatment is a problem for disabled elderly people, who, for their daily activity are dependent on carers.

Reported barriers to accessing care for the frail elderly include mobility difficulties, not knowing where to go for treatment, lack of transport, poor health and lack of an escort. ${ }^{5}$ There are really only three options for delivering dental care to elderly people who are house or bedbound. These are using a mobile dental surgery, home based/domiciliary dental care or a combination of domiciliary dental care and surgery based care where transport and an escort can be organised.

\section{DOMICILIARY CARE WITHIN THE NHS}

General dental practitioners can provide domiciliary visits for "patients whose condition requires a visit at a location other than the dental surgery' ${ }^{6}$ Some 330,000 NHS visits were conducted in the year April 1999-March 2000; 76\% of these were to people over 75 years and the total cost was

${ }^{1}$ Senior Dental Officer/Specialist in Prosthodontics, Hertfordshire Partnership Trust CDS

Correspondence to: Dr Debra Simons, Community Dental

Service, The Harmony Dental Unit, Level 2, Moynihan Block, St Albans City Hospital, St Albans, Herts AL3 5PN

\section{Refereed Paper}

Received 09.04.02; Accepted 23.09.02

๑ British Dental Journal 2003; 194: 137-138
£9.6 million. ${ }^{7}$ However the Dental Practice Board has now restricted the travel claims for domiciliary visits to a maximum of 2 a day per dentist. ${ }^{8}$

Restricting GDPs visiting house/bedbound patients potentially leaves a group of the population, that is rapidly increasing in size but unable to access dental care. It is anticipated by those working in the Community Dental Service (CDS) that much of the burden will fall on this service. Unfortunately the CDS is constrained in the amount of domiciliary care it can provide because it is a small service and has other commitments. ${ }^{9}$ In the year 2000 , the area of St Albans, West Hertfordshire in which I work, had a population of 134,926 with $19,923(14.8 \%)$ of residents over 65 years of age. The CDS in this locality consisted of three dentists, employed part-time, the dentists working in other parts of the district during the rest of the week. There were four sessions of 3.5 hours during which domiciliary visits are conducted. This time is for visits both to existing housebound patients, at home, in day centres, residential/nursing homes, and also for new referrals. A retrospective audit of new referrals of elderly people requiring domiciliary care, in this one area of West Hertfordshire
CDS was carried out to ascertain the numbers of new patients needing care and whether the service was meeting the demand.

\section{DOMICILIARY AUDIT}

Over a 20 month period (1.4.20001.11.2001) all new referrals were audited, using the British Society for Disability and Oral Health: Domiciliary Referral Form. ${ }^{10}$ During this period there were 283 new referrals that came from four sources (Table 1). One hundred and eighty-five (65.4\%) of

\begin{tabular}{ll} 
Table 1 Places clients referred from \\
\hline Hospital & $69(24.4 \%)$ \\
Own Home & $82(29.0 \%)$ \\
Residential/Nursing home & $96(33.9 \%)$ \\
Day centre/lunch clubs & $36(12.7 \%)^{*}$ \\
${ }^{*} P<0.05$ &
\end{tabular}

the referrals were female and 98 (34.6\%) male. One hundred and three people (36.4\%) were referred by qualified nurses, either community or hospital based. Ninety-nine (35\%) were referred by carers, 27 (9.5\%) by family, $23(8.1 \%)$ referred themselves, 30 $(10.6 \%)$ people were referred by their GDP who either felt unable to treat them or who 


\begin{tabular}{lrr}
\begin{tabular}{l} 
Table 2: The oral problems that prompted the contact \\
\hline Clients
\end{tabular} & \multicolumn{1}{c}{ Complaint } \\
\hline Losing weight/not eating & 19 & $(6.7 \%)$ \\
Abscess/Swelling/Pyrexia & 8 & $(2.8 \%)$ \\
Toothache/Pain & 59 & $(20.8 \%)$ \\
Trauma & 0 & \\
Lost crown & 13 & $(4.6 \%)$ \\
Tooth decay & 22 & $(7.8 \%)$ \\
Lost filling & 16 & $(5.7 \%)$ \\
Lost dentures & 12 & $(4.2 \%)$ \\
Loose teeth & 20 & $(7.1 \%)$ \\
Dental check up & 43 & $(15.2 \%)$ \\
Loose/uncomfortable dentures & 40 & $(14.1 \%)$ \\
Fractured teeth/decoronated not due to trauma & 31 & $(11.0 \%)$
\end{tabular}

did not do domiciliary visits. Only $1(0.4 \%)$ referral came from a GMP.

The mean age of the patients was $74.2 \pm 17.1$ years (females $76.3 \pm 16.9$, males $70.2 \pm 16.9$ ). The reasons they were house/bedbound fell into three categories as shown in Table 3, and the types of oral problems experienced can be seen in Table 2. One hundred and twenty-two $(43.1 \%)$ of the oral problems were classified as urgent, this was assessed by either the referring person or the person receiving the message, as being in pain, unable to eat, suffering from swelling, trauma or from pyrexia. One hundred and sixty-one (56.9\%) were non-urgent.

\section{HOW QUICKLY DID THE SERVICE RESPOND?}

All people with complaints that were considered urgent were contacted by a dentist that day. Sixty-three $(22.3 \%)$ people were visited that day. Sixty-two (21.9\%) were seen the following day, a total of 160 (56.5\%) people were visited within 2 days. Eighty-two of the referrals were seen within 1 week. People complaining of problems that were considered to be urgent were seen significantly $(P<$ 0.0001 ) sooner than those people who had non-urgent problems.

The referral forms, despite whoever in the department received the telephone contact and completed them, were useful in prioritising the clients. The speed of response to the request related only to the oral problem, it did not relate to where the patient was residing, to their medical history, to whom referred them, or to the month of referral or their age or gender. This shows that the service was equitable and was based purely on oral need and not on any other factor such as convenience to the clinic.

Ideally all oral problems that were assessed as urgent should be seen that working day. However, all people complaining of an abscess/swelling/weight loss

Table 3 Reason for being house/bedbound
Physically disabled

Mental health problems

Medical Illness

or not eating were seen that day. It was only 'toothaches' that were less severe/or intermittent that were seen later. Adjusting for this and re-analysing, shows all severe pain and urgent referrals were seen that working day and that possibly the criteria needs to be defined more precisely. Alternatively, more time could be allocated, so that all 'toothaches' would be seen that day. However, this would require increased manpower and could result in dentists without patients to visit, due to the variation in number of new referrals. It also may not provide a significant clinical gain to the clients.

\section{WHAT DID THE AUDIT SHOW ?}

The audit appears to show that this CDS was able to meet the demands of new domiciliary referrals, but it does not indicate whether this was at the expense of existing house/bedbound clients. The domiciliary service provided care to people who would otherwise not receive treatment, but there are restrictions to the service. The cost of portable equipment is high, there are limited treatment options, less clients can be seen in a day than in a clinic and the physical strain of lifting and transporting the equipment should not be underestimated. Also the audit does not reflect house/bedbound people who are unaware of the service as we were only responding to demand. This audit does not reflect the treatment need of house/bedbound people. Also the work carried out was in addition to domiciliary care provided to patients that were existing CDS clients, these clients may have experienced delays in receiving care as a result. As the size of this group increases greater demands are expected on the service.

\section{WHAT ABOUT THE FUTURE ?}

Oral health is an important factor in maintaining health and quality of life among functionally dependent elderly people. ${ }^{11}$ Oral health services should not be provided just in response to demand but organised and developed to provide continuous adequate care. We need to address the deficiencies in providing oral health care services to this growing proportion of the population. Early detection of problems, prevention and treatment for all elderly people whether functionally able or dependent is required.

As Schou et al. ${ }^{12}$ state: 'Most current oral health care services were set up and most providers educated before geriatric dentistry came into focus. It is now necessary and high time to redesign services and to re-educate providers to be able to meet the rather diversified needs of a large and growing heterogeneous older population ... The achievement of such a service goes beyond what the dental profession can do alone. It requires the involvement and willingness of other healthcare professionals, health service purchasers and carers of elderly people.'

The author thanks all the dentists and dental nurses working for West Hertfordshire CDS, especially, D. Knott, T. Spencer, S. Benton, P. Tabor, Z. Chaudhry, C. Underwood, B. Hutton. Thanks are also given to Professor EAM Kidd for all her support.

1. OPCS 1997. Mid-1997 - Population Estimates. London: HMSO publications.

2. Sheiham A. Dentistry for an ageing population: Responsibilities and future trends. Dent Update 1990; 17: 70-76.

3. Fiske J. The delivery of oral care services to elderly people living in a noninstitutionalised setting. J Public Health Dent 2000: 60: 321-325.

4. Steele J G, Sheiham A, Marcenes W, Walls A W G. National Diet and Nutrition Survey: people aged 65 years and over. Volume 2: Report of the oral health survey. London: TSO, 1998.

5. Lester V, Ashley FP, Gibbons D E. The relationship between sociodental indices of handicap, felt need for dental treatment and dental state in a group of frail and functionally dependent older adults. Community Dent Oral Epidemiol 1998; 26: 155-159.

6. Department of Health, 1999. Statement of dental renumeration.

7. Dental Practice Board, 2000. Digest of statistics.

8. Statement of Remuneration Dental Practice Board, 2000.

9. Maddick I, Fox B. In: An interdisciplinaryapproach to geriatric dentistry; Oral Health and Ageing. Tryon A F (ed). Littleton Massachuetts: PSG Publishing company Inc, 1986.

10. BSDH. Guidelines for standards of dental care for people with disabilities. British Society of Dentistry for the Handicapped, 1996.

11. Frenkel H, Harvey I, Newcombe R G. Oral health care among nursing home residents in Avon. Gerodont 2000; 17: 33-38.

12. Schou L, Holm-Pedersen P, Lang N P. In: Textbook of Gerodontology; Preventive dental care for elderly people. Munksgaard, 1997. 